\title{
Structural Studies on the Rare Earth Carboxylates. 24. The Crystal and Molecular Structure of Hexaaquafumarato- dimaleatodineodymium(III) Hexahydrate
}

\author{
EVA HANSSON and CHRISTINA THÖRNQWIST
}

Physical and Inorganic Chemistry 1, Chemical Center, University of Lund, P.0.B. 740, S-220 07 Lund 7, Sweden

The crystal and molecular structure of $\mathrm{Nd}_{2}\left(\mathrm{C}_{4} \mathrm{H}_{2} \mathrm{O}_{4}\right)_{3} \cdot 12 \mathrm{H}_{2} \mathrm{O}$ has been determined from three-dimensional photographic $\mathrm{X}$-ray data. One formula unit crystallizes in a triclinic unit cell with dimensions $a=6.195(1) \AA, b=11.260(3)$ $\AA, c=10.709(2) \AA, \alpha=110.39(2)^{\circ}, \beta=90.29(2)^{\circ}$, and $\gamma=79.32(2)^{\circ}$. The space group is $P \overline{1}$. The structure contains the maleate ion and the fumarate ion in the ratio $2: 1$. It is composed of infinite neodymium-maleate-fumarate layers joined together by hydrogen bonds via the lattice water molecules. The neodymium ion is coordinated by six carboxylate and three water oxygens forming a distorted monocapped square antiprism. The $\mathrm{Nd}-\mathrm{O}$ bond distances are in the range $2.43-2.62 \AA$.

Maleate, malonate, and oxalate ions are potential chelating ligands forming chelates with seven, six, and five members, respectively. In solution their complexes with the trivalent lanthanoid ions show the expected decrease in stability with increasing ring size, i.e. oxalate $>$ malonate $>$ maleate. ${ }^{1-3}$ The decrease in stability between the oxalate and malonate chelates is reflected in the solid state. Thus, while all oxalate ions in $\mathrm{M}_{2} \mathrm{Ox}_{3} \cdot n \mathrm{H}_{2} \mathrm{O} \quad(\mathrm{M}=$ lanthanoid ion) form five-membered chelate rings ${ }^{4,5}$ only part of the malonate ions in $\mathrm{M}_{2} \mathrm{mal}_{3} \cdot n \mathrm{H}_{2} \mathrm{O}$ form six-membered rings. ${ }^{6-8}$ The non-chelated malonate ions are bound to $\mathrm{M}^{3+}$ through both oxygens of one carboxylate group. The presence of chelating carboxylate groups in these complexes results in fairly irregular coordination polyhedra.

The present investigation was undertaken in order to determine how the maleate ion is bound

Acta Chem. Scand. A 29 (1975) No. 10 to $\mathrm{M}^{3+}$ and to study the geometry of the coordination polyhedron formed.

Another point of interest is the conformation of the maleate ion. Two different conformational patterns for the ion have been reported. In $\mathrm{Cu}$-maleate. $\mathrm{H}_{2} \mathrm{O}$, where the maleate ion forms a seven-membered chelate ring, the two carboxylate groups are twisted by $46^{\circ}$ out of the carbon chain plane. ${ }^{9}$ In $\mathrm{Li}_{2}$ maleate. $2 \mathrm{H}_{2} \mathrm{O}$, $\mathrm{Na}_{2}$ maleate. $\mathrm{H}_{2} \mathrm{O}$, and Cd-maleate. $2 \mathrm{H}_{2} \mathrm{O}$, where no chelate is formed, one carboxylate group lies approximately in the carbon chain plane, while the other one is twisted by $61-84^{\circ}$ out of this plane. ${ }^{10-12}$

\section{EXPERIMENTAL}

Preparation and analysis. Water solutions of neodymium nitrate and maleic acid were mixed in the molar ratio $1: 3$ and the $\mathrm{pH}$ was adjusted to 3 with dilute ammonia. Slow evaporation at room temperature resulted in a mixture of prismatic crystals of NMF (the title compound) and aggregates of irregular crystals of another neodymium compound (phase 2). The latter crystals were of very poor quality and could not be used for single crystal work. It was noticed that the crystals of NMF were formed at the initial stage of the precipitation, and pure NMF could be filtered off before the precipitation of phase 2 started. The amount of NMF obtained in this way corresponds to a content of $5 \%$ fumaric acid in the maleic acid used. NMR-spectra of the acid show, however, that the content of fumaric acid is at most $0.5 \%$. Isomerization of the maleate ion thus seems to occur during the crystallization. (Found: $\mathrm{Nd}$ 33.1; C 17.6; $\mathrm{H}$ 4.5. Calc for $\mathrm{Nd}_{2}\left(\mathrm{C}_{4} \mathrm{H}_{2} \mathrm{O}_{4}\right)_{3} .12 \mathrm{H}_{2} \mathrm{O}$ (846.6): Nd 34.1; C 17.0; H 3.5). 
$X$-Ray diffraction work. A prismatic crystal of the dimensions $0.25 \times 0.08 \times 0.11 \mathrm{~mm}^{3}$, mounted along the $0.25 \mathrm{~mm}$ edge, was used in recording the layers $0 k l-5 k l$.

Non-integrated, equi-inclination Weissenberg photographs were taken with Ni-filtered Cu-radiation using the multi-film technique. 2200 independent reflexions were recorded representing about $70 \%$ of the possible number in the investigated reciprocal region. The intensities of the reflexions were measured visually by comparison with a calibrated scale. The data were corrected for the Lorentz, polarization and absorption effects. The linear absorption coefficient is 273 $\mathrm{cm}^{-1}$ and the transmission factors, evaluated by numerical integration, ${ }^{18}$ were in the range $0.10-0.34$.

Powder photographs were taken at room temperature with a Guinier-Hägg camera of radius $5.00 \mathrm{~cm}$ using $\mathrm{Cu} K \alpha$ radiation $(\lambda=1.5405$ $\AA)$. Lead nitrate (cubic, $a=7.8568 \AA$ ) was used as standard.

NMF crystallizes in the Laue class $\overline{1}$. The possible space groups are thus $P 1$ (No. 1) and $P \overline{1}\left(\right.$ No. 2). ${ }^{13}$ The structure was assumed to be centrosymmetric and the subsequent calculations did not contradict this assumption. The unit cell dimensions were obtained by a least squares treatment of the powder data, minimizing $\sum w\left(\sin ^{2} \theta_{0}-\sin ^{2} \theta_{c}\right)^{2}$ with weights $w=$ $1 / \sin ^{2} 2 \theta_{0}$

The unit cell dimensions for $\mathrm{Nd}_{2}\left(\mathrm{C}_{4} \mathrm{H}_{2} \mathrm{O}_{4}\right)_{3}$. $12 \mathrm{H}_{2} \mathrm{O}$ are,

$a=6.195(1) \AA, b=11.260(3) \AA, c=10.709(2) \AA$, $\alpha=110.39(2)^{\circ}, \beta=90.29(2)^{\circ}$, and $\gamma=79.32(2)^{\circ}$.

\section{DETERMINATION AND REFINEMENT OF THE STRUCTURE}

The position of neodymium was found from a three-dimensional Patterson synthesis. After least-squares refinement of the preliminary atomic parameters of neodymium and the interlayer scale factors, a three-dimensional difference synthesis gave the positions of the oxygen and carbon atoms.

The interlayer scale factors, the atomic coordinates, and the isotropic temperature factors for all atoms were improved by least squares refinement. The quantity $\sum w\left(\left|\boldsymbol{F}_{\mathrm{o}}\right|-\left|\boldsymbol{F}_{\mathrm{c}}\right|\right)^{2}$ was minimized, with weights $w$ chosen according to Cruickshank. ${ }^{14}$ Reflexions not obeying the condition $0.80 \leq\left|F_{\mathrm{o}}\right| /\left|F_{\mathrm{c}}\right| \leq 1.25$ were given zero weight. An analysis of the weighting scheme used is given in Table 1. The atomic scattering factors for $\mathrm{O}$ and $\mathrm{C}$ were taken from International Tables ${ }^{15}$ and that for Nd from Cromer et al. ${ }^{18}$ After refinement the value of the conventional discrepancy index $R=\sum\left\|F_{\mathrm{o}}|-| F_{\mathrm{c}}\right\| \mid$ $\sum\left|F_{\mathrm{o}}\right|$ was 0.086 and the weighted $R$-factor $w R=\left[\sum w\left(\left|F_{\mathrm{o}}\right|-\left|F_{\mathrm{c}}\right|\right)^{2} / \sum w\left|F_{\mathrm{o}}\right|^{2}\right]^{\frac{1}{2}}$ was 0.101 .

Further refinement using anisotropic thermal parameters for $\mathrm{Nd}$ resulted in the following $R$-values: $R=0.079$ and $w R=0.094$ and it was considered reasonable to assign anisotropic temperature factors for the neodymium atom. The shifts of all parameters were less than $0.5 \%$ of their estimated standard deviations in the last cycle of refinement. It was not possible to locate the hydrogen atoms.

The final atomic parameters with their estimated standard deviations are given in Table 2. A difference map based on these parameters showed a peak about $5 \mathrm{e} / \AA^{3}$ at the position of neodymium and spurious peaks about $2 \mathrm{e} / \AA^{3}$ in other regions. The final structure factor list is available on request.

All computations were performed on the UNIVAC 1108 computer in Lund, Sweden,

Table 1. Analysis of the weighting scheme $w=1 /\left(1+\left|F_{\mathrm{o}}\right|+0.03\left|F_{\mathrm{o}}\right|^{2}+0.001\left|F_{\mathrm{o}}\right|^{3}\right)$. The averages $\bar{w} \Delta^{2}$, where $\Delta=\left|F_{\mathrm{o}}\right|-\left|F_{\mathrm{c}}\right|$, are normalized.

\begin{tabular}{llllll}
\hline $\begin{array}{l}\text { Interval } \\
\left|F_{\text {o }}\right|\end{array}$ & $\begin{array}{l}\text { Number of } \\
\text { reflexions }\end{array}$ & $\overline{w \Delta^{2}}$ & $\begin{array}{l}\text { Interval } \\
\sin \theta\end{array}$ & $\begin{array}{l}\text { Number of } \\
\text { reflexions }\end{array}$ & $\overline{w \Delta^{2}}$ \\
\hline $0-14$ & 197 & 0.84 & $0.00-0.37$ & 79 & 1.46 \\
$14-19$ & 185 & 1.03 & $0.37-0.47$ & 131 & 1.11 \\
$19-24$ & 203 & 1.02 & $0.47-0.54$ & 139 & 0.90 \\
$24-28$ & 208 & 1.18 & $0.54-0.59$ & 143 & 0.85 \\
$28-32$ & 211 & 0.90 & $0.59-0.64$ & 135 & 1.917 \\
$32-37$ & 207 & 0.87 & $0.64-0.68$ & 139 & 0.82 \\
$37-43$ & 208 & 0.96 & $0.68-0.71$ & 142 & 0.81 \\
$43-50$ & 212 & 1.01 & $0.71-0.74$ & 131 & 1.96 \\
$50-62$ & 213 & 1.10 & $0.74-0.77$ & 120 & 107 \\
$62-151$ & 197 & 1.09 & $0.77-0.80$ & 107 & \\
\hline
\end{tabular}


Table 2. Atomic parameters with estimated standard deviation for $\mathrm{Nd}_{2}\left(\mathrm{H}_{2} \mathrm{C}_{4} \mathrm{O}_{4}\right)_{3} \cdot 12 \mathrm{H}_{2} \mathrm{O}$.

\begin{tabular}{|c|c|c|c|c|c|}
\hline Atom & Group & $x \times 10^{4}$ & $y \times 10^{4}$ & $z \times 10^{4}$ & $B / \AA^{2}$ \\
\hline Nd & & $42.6(8)$ & $2194.5(4)$ & $1264.8(4)$ & $(1.46)^{a}$ \\
\hline $\mathrm{O}(1)$ & $\mathrm{COO}^{-}$ & $3657(13)$ & $757(6)$ & $1462(6)$ & $2.3(1)$ \\
\hline $\mathrm{O}(2)$ & $\mathrm{COO}^{-}$ & $1639(14)$ & $1881(7)$ & $3314(7)$ & $2.9(1)$ \\
\hline O(3) & $\mathrm{COO}^{-}$ & $8046(14)$ & $-1626(7)$ & $957(7)$ & $2.7(1)$ \\
\hline $\mathbf{O}(4)$ & $\mathrm{COO}^{-}$ & $8940(15)$ & $229(8)$ & $1247(8)$ & $3.2(1)$ \\
\hline $\mathrm{O}(5)$ & $\mathrm{COO}^{-}$ & $-3352(14)$ & $3129(7)$ & $2893(7)$ & $2.7(1)$ \\
\hline$O(6)$ & $\mathrm{COO}^{-}$ & $-888(15)$ & $4348(8)$ & $3331(8)$ & 3.2(1) \\
\hline$O(7)$ & $\mathrm{H}_{3} \mathrm{O}$ & $3132(14)$ & $3420(7)$ & $1498(7)$ & $2.6(1)$ \\
\hline$O(8)$ & $\mathrm{H}_{2} \mathrm{O}$ & $-1325(15)$ & $4053(7)$ & $591(8)$ & $3.1(1)$ \\
\hline$O(9)$ & $\mathrm{H}_{2} \mathrm{O}$ & $-3049(14)$ & $1788(7)$ & $-218(7)$ & $2.8(1)$ \\
\hline$O(10)$ & $\mathrm{H}_{2} \mathrm{O}$ & $-415(17)$ & $6863(9)$ & $4078(9)$ & $3.5(2)$ \\
\hline O(l1) & $\mathrm{H}_{2} \mathrm{O}$ & $2798(16)$ & $6032(8)$ & $1929(8)$ & 3.3(1) \\
\hline $0(12)$ & $\mathrm{H}_{2}^{2} \mathrm{O}$ & $-3126(16)$ & $6642(8)$ & $2029(8)$ & $3.5(2)$ \\
\hline$C(1)$ & $\mathrm{COO}^{-}$ & $\mathbf{3 4 3 9}(20)$ & $1118(10)$ & $2715(10)$ & $2.5(2)$ \\
\hline $\mathrm{C}(2)$ & $=\mathrm{CH}$. & $5087(23)$ & $705(11)$ & $3534(11)$ & $3.1(2)$ \\
\hline C(3) & $=\mathrm{CH}$. & $7047(21)$ & $21(11)$ & $3093(10)$ & $2.8(2)$ \\
\hline C(4) & $\mathrm{COO}^{-}$ & $7997(18)$ & $-489(9)$ & $1655(9)$ & $2.0(1)$ \\
\hline C(5) & $\mathrm{COO}^{-}$ & $-2667(18)$ & $4125(9)$ & $3621(9)$ & $2.0(1)$ \\
\hline$C(6)$ & $=\mathrm{CH}$. & $-4071(20)$ & $5072(10)$ & $4832(10)$ & $2.5(2)$ \\
\hline
\end{tabular}

a The anisotropic thermal parameters for neodymium, calculated from the expression: $\exp \left[-\left(h^{2} \beta_{11}+\right.\right.$ $\left.\left.2 h k \beta_{12}+\cdots\right)\right]$ are $\beta_{11}=0.00860(95), \beta_{22}=0.00413(7), \beta_{33}=0.00431(6), \beta_{12}=-0.00108(7), \beta_{13}=0.00134(7)$, and $\beta_{23}=0.00195(4)$, resulting in root mean square displacements along the principal axis of the thermal ellipsoid $R_{1}=0.1621(\AA), R_{2}=0.1073(\AA)$, and $R_{3}=0.1441(\AA)$.

using the programmes PIRUM, ${ }^{17}$ CELSIU, DRF, DATAP2, LALS, DISTAN, PLANE, and ORTEP. ${ }^{18}$

\section{DESCRIPTION AND DISCUSSION OF THE STRUCTURE}

The superscripts (i) - (vii) are used to indicate the following equivalent sites in the structure.
$x, y, z$
(i) $\bar{x}+1, \bar{y}, \bar{z}$
(ii) $x-1, y, z$
(iii) $\bar{x}-1, \bar{y}+1, \bar{z}+1$
(iv) $x+1, y, z$
(v) $\bar{x}, \bar{y}, \bar{z}$
(vi) $\bar{x}, \bar{y}+1, \bar{z}$
(vii) $\bar{x}, \bar{y}+1, \bar{z}+1$

where $x, y, z$ are the atomic coordinate given in Table 2. The numbering of the atoms constituting the two ligands maleate and fumarate is shown in Fig. 1.

The structure of NMF is shown in Fig. 2. The maleate ion is not chelated. One of its carboxylate groups, $\mathrm{O}(3)-\mathrm{C}(4)-\mathrm{O}(4)$, holds the neodymium ions in pairs, and the oxygens of the other, $\mathrm{O}(1)-\mathrm{C}(1)-\mathrm{O}(2)$, are coordinated to one of the neodymium ions in the next pair along the $a$-axis. The Nd-maleate chains built in this way are linked together to layers by the fumarate ions. Adjacent layers are joined by hydrogen bonds via the lattice water molecules $O(10), O(11)$, and $O(12)$. These water molecules are in turn hydrogen bonded to each other forming chains parallel to $a$.

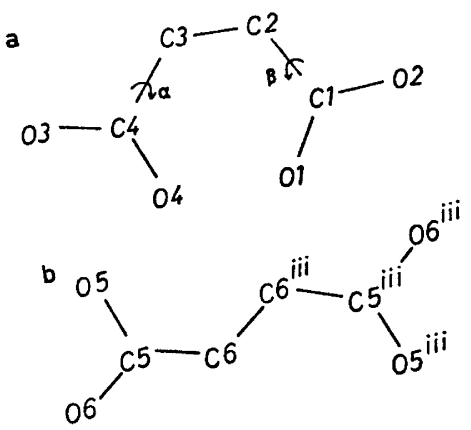

Fig. 1. Designation of the atoms in the two different ligands. a. The maleate ion; $b$. The fumarate ion. 


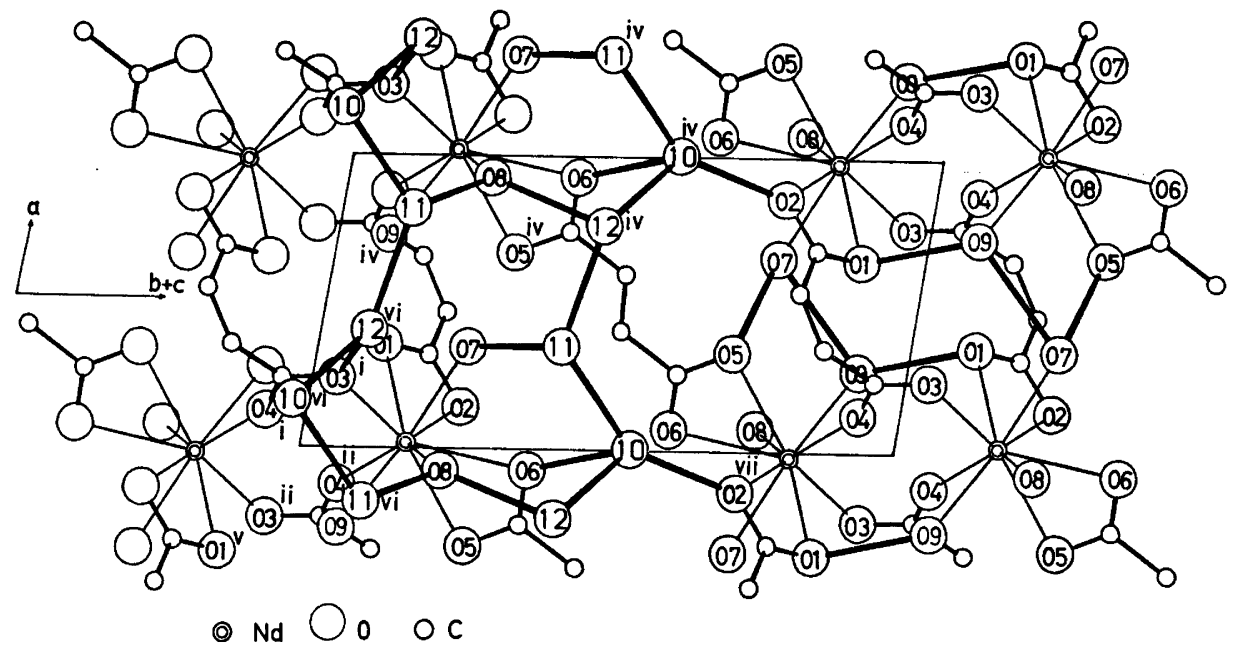

Fig. 2. The Nd-maleate-fumarate layer and the hydrogen bonding. The Nd-maleate chains around $y=z=0$ and $y=z=1$ linked by the fumarate ion at $\left(\frac{1}{2}, \frac{1}{2}, \frac{1}{2}\right)$ are projected on $(0,1, \overline{1})$. The lattice water molecules around $y=\frac{1}{2}, z=0$ and their hydrogen bonding are shown in the right part of the figure. The hydrogen bonds within the Nd-maleate chain are shown in the left part. Hydrogen bonds are indicated by broad lines.
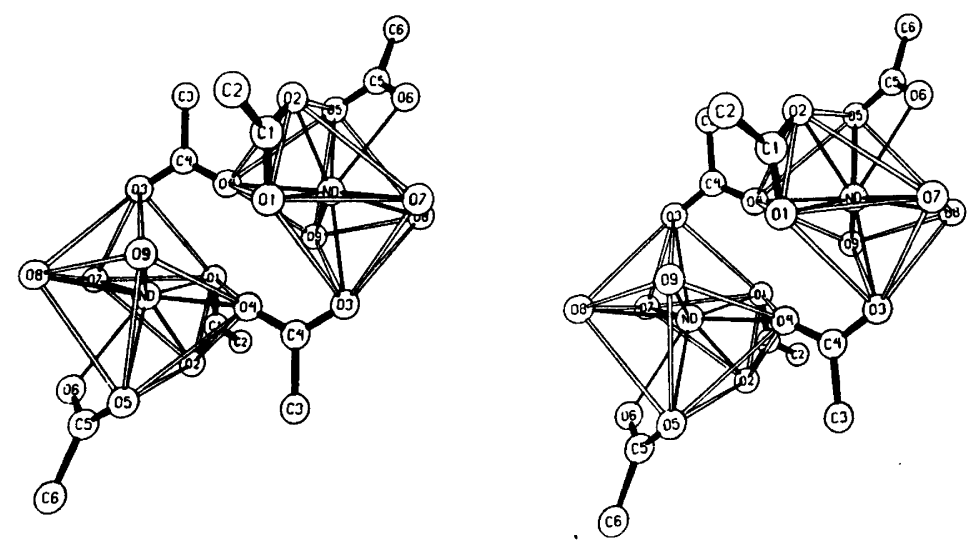

Fig. 3. A stereoscopic pair of drawings showing the coordination polyhedra around $\mathrm{Nd}$ and $\mathrm{Nd}^{\mathrm{v}}$. The edges of the square antiprism are indicated by open lines.

The coordination polyhedron. There are nine oxygens coordinated to each neodymium ion, cf. Fig. 3. The carboxylate groups $\mathrm{O}(1)-\mathrm{C}(1)-$ $O(2)$ and $O(5)-C(5)-O(6)$ each form a fourmembered chelate ring with the metal ion. The carboxylate groups $\mathrm{O}(3)-\mathrm{C}(4)-\mathrm{O}(4)$ are bridging between the two neodymium ions. The remaining three oxygens are the water oxygens $O(7), O(8)$, and $O(9)$. Besides the two carboxylate bridges the two polyhedra are coupled to each other by hydrogen bonds between $\mathrm{O}(1)$ and $\mathrm{O}(9)$. The $\mathrm{Nd}-\mathrm{O}$ bond distances are in the range $2.43-2.62 \AA$, with the average $2.51 \AA$. The geometry of the bridge $\mathrm{Nd}-\mathrm{O}\left(3^{\mathrm{i}}\right)-\mathrm{C}\left(4^{\mathrm{i}}\right)-\mathrm{O}\left(4^{\mathrm{i}}\right)-\mathrm{Nd}^{\mathrm{y}}$ brings the oxygen $\mathrm{O}\left(4^{\mathrm{i}}\right)$ fairly close to $\mathrm{Nd}$, but the distance $\mathrm{Nd}-\mathrm{O}\left(4^{\mathrm{i}}\right), 3.06 \AA$, seems to be too long to be an bond distance. Moore et al. ${ }^{19}$ considered a $\mathrm{La}-\mathrm{O}$ distance of $2.92 \AA$ in a carboxylate bridge of the present type to represent at most a weak lanthanum-oxygen interaction while the corresponding $\mathrm{Sm}-\mathrm{O}$ 
Table 3. Selected distance $(\AA)$ and angles $\left({ }^{\circ}\right)$ with their estimated standard deviations.

A. The coordination polyhedron

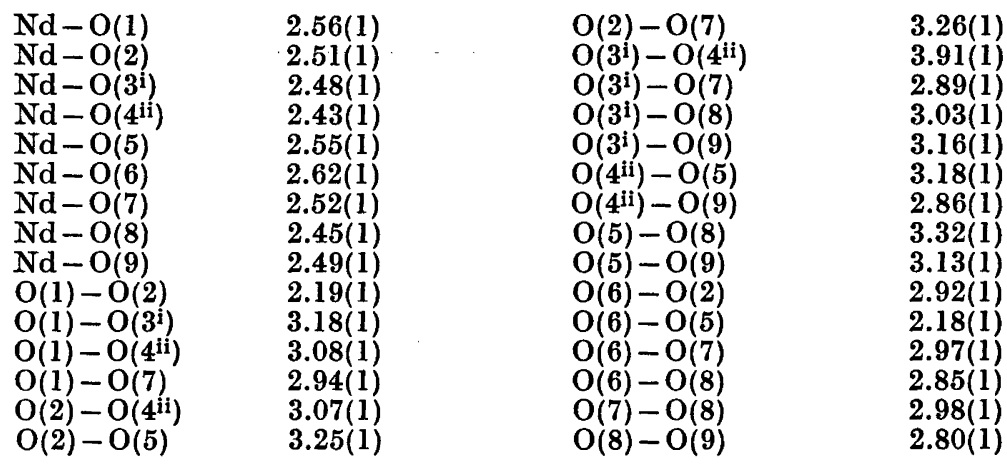

B. The maleate ion

$\begin{array}{ll}\mathrm{O}(1)-\mathrm{O}(2) & 2.19(1) \\ \mathrm{C}(1)-\mathrm{O}(1) & 1.26(1) \\ \mathrm{C}(1)-\mathrm{O}(2) & 1.29(1) \\ \mathrm{C}(1)-\mathrm{C}(2) & 1.46(2) \\ \mathrm{C}(2)-\mathrm{C}(3) & 1.30(2) \\ \mathrm{C}(3)-\mathrm{C}(4) & 1.52(1) \\ \mathrm{C}(4)-\mathrm{O}(3) & 1.23(1) \\ \mathrm{C}(4)-\mathrm{O}(4) & 1.27(1) \\ \mathrm{O}(3)-\mathrm{O}(4) & 2.18(1)\end{array}$

$\mathrm{O}(1)-\mathrm{C}(1)-\mathrm{O}(2) \quad 118(1)$

$\mathrm{O}(1)-\mathrm{C}(1)-\mathrm{C}(2) \quad 124(1)$

$\mathrm{O}(2)-\mathrm{C}(1)-\mathrm{C}(2) \quad 118(1)$

$\mathrm{C}(1)-\mathrm{C}(2)-\mathrm{C}(3) \quad 125(1)$

$\mathrm{C}(2)-\mathrm{C}(3)-\mathrm{C}(4) \quad 126(1)$

$\mathrm{C}(3)-\mathrm{C}(4)-\mathrm{O}(3) \quad 120(1)$

$\mathrm{C}(3)-\mathrm{C}(4)-\mathrm{O}(4) \quad 119(1)$

$\mathrm{O}(3)-\mathrm{C}(4)-\mathrm{O}(4) \quad 121(1)$

C. The fumarate ion

$\begin{array}{ll}\mathrm{O}(5)-\mathrm{O}(6) & 2.18(1) \\ \mathrm{C}(5)-\mathrm{O}(6) & 1.24(1) \\ \mathrm{C}(5)-\mathrm{O}(5) & 1.27(1) \\ \mathrm{C}(5)-\mathrm{C}(6) & 1.51(1) \\ \mathrm{C}(6)-\mathrm{C}\left(6^{\mathrm{iii}}\right) & 1.26(2)\end{array}$

$\mathrm{O}(5)-\mathrm{C}(5)-\mathrm{O}(6) \quad 121(1)$

$\mathrm{O}(5)-\mathrm{C}(5)-\mathrm{C}(6) \quad 120(1)$

$\mathrm{O}(6)-\mathrm{C}(5)-\mathrm{C}(6) \quad 120(1)$

$\mathrm{C}(6)-\mathrm{C}\left(6^{\mathrm{iii}}\right) \quad 1.26(2)$

$\mathrm{C}(5)-\mathrm{C}(6)-\mathrm{C}\left(6^{\mathrm{iii}}\right) \quad 123(1)$

D. The possible hydrogen bonds

\begin{tabular}{ll}
$O(7)-O\left(5^{\mathrm{iv}}\right)$ & $2.67(1)$ \\
$O(7)-O(11)$ & $2.78(1)$ \\
$O(8)-O\left(11^{\mathrm{vi}}\right)$ & $2.82(1)$ \\
$O(8)-O(12)$ & $2.79(1)$ \\
$O(9)-O\left(1^{\mathrm{v}}\right)$ & $2.81(1)$ \\
$O\left(9^{\mathbf{i}^{\mathrm{v}}}\right)-O(7)$ & $2.90(1)$ \\
$O(10)-O\left(2^{\mathrm{vii}}\right)$ & $2.69(1)$ \\
$O(10)-O(6)$ & $2.73(1)$ \\
$O(11)-O(10)$ & $2.83(1)$ \\
$O(11)-O\left(12^{\mathrm{vi}}\right)$ & $2.73(1)$ \\
$O\left(12^{\mathrm{v}}\right)-0\left(3^{\mathrm{i}}\right)$ & $2.78(1)$ \\
$O(12)-O(10)$ & $2.73(1)$ \\
\hline
\end{tabular}

$\begin{array}{lr}O\left(5^{\mathrm{iv}}\right)-\mathrm{O}(7)-\mathrm{O}(11) & 97.8(3) \\ \mathrm{O}\left(11^{\mathrm{vi}}\right)-\mathrm{O}(8)-\mathrm{O}(12) & 98.1(4) \\ \mathrm{O}\left(1^{\mathrm{i}}\right)-\mathrm{O}\left(9^{\mathrm{iv}}\right)-\mathrm{O}(7) & 111.8(4) \\ \mathrm{O}\left(2^{\mathrm{vii}}\right)-\mathrm{O}(10)-\mathrm{O}(6) & 110.2(4) \\ \mathrm{O}(10)-\mathrm{O}(11)-\mathrm{O}\left(12^{\mathrm{iv}}\right) & 126.3(4) \\ \mathrm{O}\left(3^{\mathrm{i}}\right)-\mathrm{O}\left(12^{\mathrm{vi}}\right)-\mathrm{O}\left(10^{\mathrm{vi}}\right) & 101.9(4)\end{array}$

Acta Chem. Scand. A 29 (1975) No. 10 
Table 4. Deviation in $\AA$ from least squares planes within the coordination polyhedron and the maleate and fumarate ions. The atoms defining the plane are in each case given above the asterisk.

$\begin{array}{lllll}\text { Atom Distance Atom Distance Atom } & \text { Distance }\end{array}$

A. The coordination polyhedron

$\begin{array}{lrlr}\mathrm{O}(2) & 0.16 & \mathrm{O}(1) & -0.23 \\ \mathrm{O}(5) & -0.16 & \mathrm{O}\left(4^{\mathrm{ii}}\right) & 0.26 \\ \mathrm{O}(8) & 0.17 & \mathrm{O}(9) & -0.25 \\ \mathrm{O}(7) & -0.18 & \mathrm{O}\left(3^{\mathrm{i}}\right) & 0.22 \\ * & & \mathrm{Nd} & -1.24 \\ \mathrm{Nd} & 1.10 & \mathrm{Nd} & -1.77\end{array}$

B. The maleate ion

$\begin{array}{lrlrlr}\mathrm{C}(1) & 0.00 & \mathrm{C}(2) & 0.00 & \mathrm{C}\left(3^{\mathrm{i}}\right) & 0.01 \\ \mathrm{C}(2) & 0.00 & \mathrm{C}(1) & -0.01 & \mathrm{C}\left(4^{\mathbf{1}}\right) & -0.04 \\ \mathrm{C}(3) & 0.00 & \mathrm{O}(1) & 0.00 & \mathrm{O}\left(3^{\mathbf{i}}\right) & 0.01 \\ \mathrm{C}(4) & 0.00 & \mathrm{O}(2) & 0.00 & \mathrm{O}\left(4^{\mathbf{i}}\right) & 0.01 \\ * & & * & * & \\ \mathrm{O}(1) & 0.12 & \mathrm{Nd} & -0.20 & \mathrm{Nd} & 0.09 \\ \mathrm{O}(2) & -0.11 & & & \mathrm{Nd}^{\mathbf{v}} & -0.05 \\ \mathrm{O}(3) & 1.05 & & & & \\ \mathrm{O}(4) & -1.11 & & & & \end{array}$

C. The fumarate ion

\begin{tabular}{|c|c|}
\hline$O(5)$ & 0.00 \\
\hline$O(6)$ & 0.01 \\
\hline C(5) & -0.01 \\
\hline$C(6)$ & -0.01 \\
\hline $\mathrm{C}\left(6^{\mathrm{iij}}\right)$ & 0.01 \\
\hline$C\left(5^{\mathrm{iii}}\right)$ & 0.01 \\
\hline $\mathbf{O}\left(5^{\mathrm{iii}}\right)$ & -0.01 \\
\hline${ }_{*}\left(5^{\mathrm{iii}}\right)$ & -0.00 \\
\hline $\mathrm{Nd}$ & -00 \\
\hline
\end{tabular}

distance of 3.22 $\AA$ was regarded as non-bonding. Similar carboxylate bridges were also found in the lanthanoid malonates $\mathrm{N}_{2} \mathrm{mal}_{3} .8 \mathrm{H}_{2} \mathrm{O},{ }^{\circ}$ $\mathrm{Nd}_{2} \mathrm{mal}_{3} \cdot 6 \mathrm{H}_{2} \mathrm{O},{ }^{7}$ and $\mathrm{Eu}_{2} \mathrm{mal}_{3} \cdot 8 \mathrm{H}_{2} \mathrm{O}^{8}$ In those structures the distances corresponding to $\mathrm{Nd} \cdots \mathrm{O}\left(4^{\mathrm{i}}\right)$ are: $\mathrm{Nd}-\mathrm{O}, 2.72$ and $2.61 \AA$; Eu-O, 2.84 $\AA$ and were regarded as bond distances.

The coordination polyhedron is an intermediate between a monocapped square antiprism (CSAP) and a tricapped trigonal prism (TCTP). The "square" faces of the antiprism are $O(1)-O\left(4^{i i}\right)-O(9)-O\left(3^{i}\right)$ and $O(2)-O(5)-$ $O(8)-O(7)$ and the triangular faces of the trigonal prism are $O\left(3^{i}\right)-O(7)-O(8)$ and
$O(2)-O(5)-O\left(4^{i i}\right)$. The angle between the "square" faces of the antiprism is $8^{\circ}$ while that between the triangular faces of the trigonal prism is $14^{\circ}$. The CSAP is outlined in Fig. 3.

The atoms defining the square base of the cap are coplanar within $\pm 0.2 \AA$ and those defining the square base of the prism are coplanar within $\pm 0.3 \AA$ (Table $4 \mathrm{~A}$ ). The two "squares" are of about the same size with average edge lengths of 3.1 and $3.2 \AA$. The noncoordinated oxygen $\mathrm{O}\left(4^{i}\right)$ is situated outside the square base of the prism.

The maleate ion. The conformation of the maleate ion is the same as in the maleate structures containing the non-chelated ion. The

Acta Chem. Scand. A 29 (1975) No. 10 
carbon chain, and the two $\mathrm{C}-\mathrm{COO}$ groups are planar within the limits of error (Table 4B). The torsion angles $\alpha$ and $\beta$ between each of the $\mathrm{C}-\mathrm{COO}$ planes and the carbon chain plane (Fig. 1) are $\alpha=-83^{\circ}$ and $\beta=6^{\circ}$. The corresponding angles in $\mathrm{Li}_{2}$ maleate are 81.4 and $7.0^{\circ}$, and in $\mathrm{Na}_{2}$ maleate 66.3 and $-16.9^{\circ} .{ }^{20}$ In Cd-maleate which contains two independent maleate ions these angles are 83.6 and $-17.5^{\circ}$ in one and 66.6 and $-15.6^{\circ}$ in the other. ${ }^{12}$ Thus, the group $\mathrm{C}(3)=\mathrm{C}(2)-\mathrm{C}(1) \mathrm{O}(1) \mathrm{O}(2)$ is approximately planar in five different environments. This finding agrees with the fact that $\mathrm{R}-\mathrm{C}-\mathrm{COO}$ groups $(\mathrm{R}=\mathrm{C}-, \mathrm{C}=, \mathrm{N}-, \mathrm{O}-$, $\mathrm{S}-$ ) are as a rule found to be planar. ${ }^{21}$ Accordingly one might expect that the second carboxylate group too lies in the plane of the carbons. However, such an arrangement seems impossible due to repulsion between the carboxylate groups.

With the bond distances and angles assumed to represent an unstrained carbon framework of the present type $\left(\mathrm{C}=\mathrm{C}-\mathrm{C}, 121.5^{\circ} ; \mathrm{C}=\mathrm{C}, 1.34\right.$ $\AA ; \mathrm{C}-\mathrm{C}, 1.49 \AA)^{22}$ and a $\mathrm{C}-\mathrm{COO}$ group unaffected by its environment, $(\mathrm{C}-\mathrm{C}-\mathrm{O}$, $\left.117.5^{\circ} ; \mathrm{C}-\mathrm{O}, 1.26 \AA\right)^{23}$ the distance $\mathrm{O}(1) \cdots \mathrm{O}(4)$ of a completely planar maleate ion would be as short as $1.60 \AA$.

Bond distances and angles within the maleate ion are given in Table 3B. The standard deviations are too large to permit any detailed discussion of the dimensions of the ion. It should be mentioned that the $\mathrm{C}=\mathrm{C}-\mathrm{C}$ angles are found to be larger than the value $121.5^{\circ}$ quoted above, in accordance with the results obtained for the alkali maleates. ${ }^{20}$

The fumarate ion. The fumarate ion has a center of symmetry and is planar within the limits of errors (Table 4C), in agreement with the empirical rule mentioned above. Planar or approximately planar fumarate groups are found also in fumaric acid ${ }^{24}$ and in hydrogen fumarates and fumarates..$^{25-28}$

The bond distances and angles in the fumarate ion (Table $3 \mathrm{C}$ ) agree with those found in other fumarate structures.

The hydrogen bonds. Regarding distances between a water oxygen and other oxygens shorter than $3.20 \AA$ and not constituting coordination polyhedron edges as possible hydrogen bond distances, there is just one suitable distance for each of the water hydrogens. The longest of these distances is $2.90 \AA$. Thus a reasonable hydrogen bond system can be chosen even though the positions of the hydrogen atoms have not been located. The two hydrogen bond acceptors of each water molecule are given in Table 3D.

The lattice water molecules, $O(10), O(11)$, and $O(12)$ are hydrogen bonded to each other forming infinite chains of the type $\cdots \mathrm{O}(12) \cdots$ $\mathrm{O}(10) \cdots \mathrm{O}(11) \cdots \mathrm{O}\left(12^{\mathrm{iv}}\right) \cdots \mathrm{O}\left(10^{\mathrm{iv}}\right) \cdots$ parallel to the $a$-axis (Fig. 2), and situated between the metal-ligand layers. Adjacent metal-ligand layers are linked by hydrogen bonds via the water molecules of these chains. The carboxylate oxygens $O(2), O(3)$, and $O(6)$ each accept one hydrogen bond from the chains, and the coordinated water molecules $O(7)$ and $O(8)$ donate one and two hydrogen bonds, respectively, to the chains.

Intra layer hydrogen bonds are formed by the water molecules $O(7)$ and $O(9)$. The bonds $O(7) \cdots O\left(5^{\text {iv }}\right)$ and $O\left(9^{\text {iv }}\right) \cdots O(7)$ link adjacent polyhedra in the $a$-direction and the bond $\mathrm{O}(9) \cdots O\left(1^{v}\right)$ links the two polyhedra of a pair as mentioned above.

Acknowledgements. This work is part of a research project supported by the Swedish Natural Science Research Council.

\section{REFERENCES}

1. Grenthe, I., Gårdhammar, G. and Rund. crantz, E. Acta Chem. Scand. 23 (1969) 93.

2. Dellien, I. Acta Chem. Scand. 27 (1973) 733.

3. Dellien, I. and Malmsten, L.-A. Acta Chem. Scand. 27 (1973) 2877.

4. Hansson, E. Acta Chem. Scand. 24 (1970) 2969.

5. Hansson, E. Acta Chem. Scand. 27 (1973) 823.

6. Hansson, E. Acta Chem. Scand. 27 (1973) 2441.

7. Hansson, E. Acta Chem. Scand. 27 (1973) 2813.

8. Hansson, E. Acta Chem. Scand. 27 (1973) 2827.

9. Prout. C. K., Carruthers, J. R. and Rossotti, F. J. C. J. Chem. Soc. A (1971) 3342.

10. Town, W. G. and Small, R. W. H. Acta Crystallogr. B 29 (1973) 1950.

11. James, M. N. G. and Williams, G. J. B. Acta Crystallogr. B 30 (1974) 1257.

12. Post, M. L. and Trotter, J. J. Chem. Soc. Dalton Trans. (1974) 674.

13. International Tables for X-Ray Crystallography, Kynoch Press, Birmingham 1969, Vol. I. 
14. Cruickshank, D. W. J. In Rollet, J. S. Ed., Computing Methods in Crystallography, Pergamon, Glasgow 1965, pp. 99-116.

15. International Tables for $X$-Ray Crystallography, Kynoch Press, Birmingham 1968, Vol. III.

16. Cromer, D. T., Larsson, A. C. and Waber, J. T. Acta Crystallogr. 17 (1964) 1044.

17. Werner, P. E. Ark. Kemi 31 (1970) 513.

18. Liminga, R. Acta Chem. Scand. 21 (1967) 1206.

19. Moore, J. W., Glick, M. D. and Baker, W. A. J. Amer. Chem. Soc. 94 (1972) 1858.

20. James, M. N. G. and Williams, G. J. B. Acta Crystallogr. B 30 (1974) 1249.

21. Oskarsson, A. Structural Studies on Solid Iminodiacetate Compounds, Thesis, Lund 1974.

22. Darlow, S. F. Acta Crystallogr. 14 (1961) 1257.

23. Hahn, T. Z. Kristallogr. 109 (1957) 4.

24. Bednowitz, A. L. and Post, B. Acta Crystallogr. 21 (1966) 566.

25. Gupta, M. P. and Sahn, R. G. Acta Crystallogr. B 26 (1970) 61 .

26. Gupta, M. P. and Sahn, R. G. Acta Crystallogr. B 26 (1970) 1964.

27. Gupta, M. P. and Sahn, B. N. Acta Crystallogr. B 26 (1970) 1969.

28. Gupta, M. P., Prasad, S. M., Sahn, R. G. and Sahn, B. N. Acta Crystallogr. B 28 (1972) 135.

Received April 1, 1975. 